\title{
8. The Australian Taxation Office Change Program: Project and Change Management Directions and Learnings, A Case Study
}

\author{
Bob Webb, Deputy Commissioner, Australian Taxation Office
}

\section{Introduction}

Corporate policies, the literature and any number of very capable consultants provide frameworks to successfully tackle project and change management.

Nobody doubts the increasing significance of project management in a world where change and flexibility at speed have become a part of life, and an expectation on all organisations. So if the literature and experience are to be believed, why is it so hard to succeed?

This chapter uses the sometimes successful, sometimes painful, but never dull experience of the Tax Office as a case study.

In particular, it tells the story of lessons from the introduction of major tax reform, and how we have drawn on that experience in the current fairly ambitious enterprise-wide Change Program.

Figure 1

The Tax Office's continuing project management journey

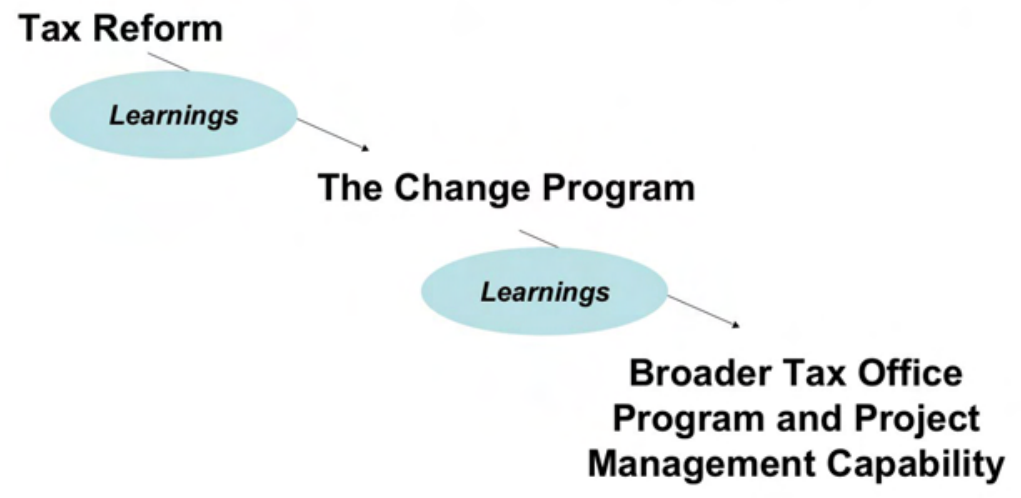


It also briefly covers how our organisational learning is continuing, as we attempt to build a practical and flexible approach to project and change management as an ongoing capability for the Tax Office. This is increasingly important to manage a growing portfolio of program and project activities.

\section{Context and Drivers for Change}

The Tax Office administers a range of revenue legislation including income tax, GST, excise and superannuation, which generates 89 per cent of Commonwealth Government revenue and about $\$ 35$ billion for the States and Territories. Less publicised is that we also provide benefits of about $\$ 4$ billion to the community. The Office has about 22,000 staff at around 60 locations around Australia. We interact with just about every segment of the community. There are fairly high annual volumes of phone enquires (11 million), returns for processing (14 million income tax returns and a similar number of activity statements), and debt collections (1.4 million for $\$ 52$ billion).

Major tax reform was announced by the Government in 1997. It was introduced primarily in 2000/2001 with the GST, the Australian Business Number (ABN) and a series of business and personal tax reforms. Three years might sound like a reasonable period to plan and deliver, but for more than half that period the Government was defining and negotiating what the actual reform was going to look like, so the period for implementation telescoped down fairly dramatically.

In hindsight we can see that, partly because of the 'telescoping', but also because of some things we just did not anticipate, our consultation processes were not fully up to the job. Our systems were outdated and fragmented, and we implemented the program internally in a quite devolved style. We had, perhaps, not appreciated how difficult it was going to be to bring about a major reform or change with that sort of fragmentation.

At one level we succeeded - all policies were delivered on time and the revenue came in - but some of adverse consequences started to manifest themselves in 2001 and 2002, particularly amongst the tax agents and business community. This is evident from some media reports of the time.

Basically tax agents said 'if things do not improve in terms of our experience of the administration, we will stop dealing electronically with the Tax Office'. They knew this would cripple our activities. Suffice to say we were building up a pretty significant set of issues around 2002 which we had to respond to.

So we took a step back and commenced the 'Listening to the Community' initiative. This took about nine months during 2002. We listened not only to our client segments - individuals, business, large business, small business - all of whom had some very different perspectives and priorities - but also to our 
staff. This involved surveys, user clinics and focus groups, and testing prototype products at creative retreats with Tax Officers and the community.

Figure 2

\section{Listening to the Community - 2002}
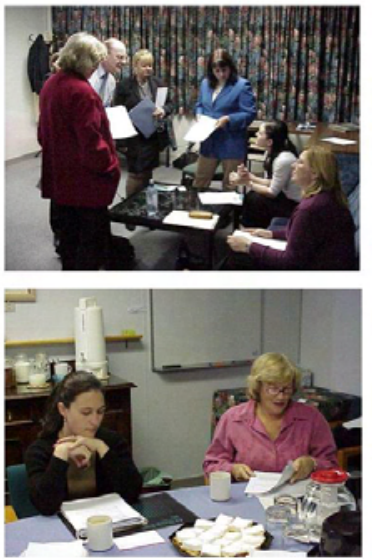

- We learned how we were not meeting taxpayer expectations

\section{- How did the process work?}

- quantitative surveys to find out how well we listened and responded to the community's concerns

- user clinics to understand administrative issues from a user perspective

- prototype products developed and tested at creative retreats involving the Tax Office and the community

- all client segments and staff

A question often asked is whether the sort of change we subsequently embarked on is best managed from the top down or the bottom up. There is no doubt that establishing the strategy and implementation I will describe later has been driven from the top down, otherwise it would not have worked at all. However if we had not had the bottom up 'listening' step first, so that we could distil an agenda to address both client and staff concerns, we could easily have missed the mark.

We distilled many messages and priorities from the listening initiative. I will use an example from the tax agents' feedback. One of the things they wanted was more detailed and on-line access to the information we hold on their clients. It became obvious that we had to do something about that issue. I will mention later how the tax agent portal, which allows tax agents to access their clients' information directly from our systems, has been the single biggest benefit to that segment of the community.

Suffice to say we got real benefit out of the listening exercise, and the findings are still a major driver of the current program.

There have been other drivers for change as follows:

- Government expectations for policy change - At any one time we have about 100 policy projects on the go, not quite as big as the tax reform period, but nevertheless quite significant; 
- Technology - The fact that technology is moving so fast which in turn is changing community expectations quite significantly; and

- Community confidence - If we do not maintain community confidence in the taxation system then we really have a problem, as the revenue base to a significant extent depends on voluntary compliance.

\section{The Easier Cheaper and More Personalised Change Program}

The Easier, Cheaper and more Personalised Change Program is the program developed to address these issues, including the priorities from listening to the community and the staff.

What is this program? It is primarily about improving the client and staff experience. However it is also about improving productivity and flexibility, to respond to both government and community needs in an ongoing way. It is a five-year program, started in 2003 after listening to the community. It covers new products and services for all segments and channels of interaction with the community.

It has had quick wins such as the tax agent portal. We realised that while some things will take until 2008 to achieve, if we were waiting until then to start the real improvements for the community, we would have long ago lost the confidence that we needed to gain and regain.

The program replaces essentially all existing Tax Office business processes and systems, front and back end. One way of typifying the change is that a call centre representative currently responding to a tax payer or tax agent enquiry may have to access anything up to 16 systems. Following the introduction of the Change Program it will be just two systems, a quite radical improvement for staff.

The program is based on enterprise-wide approaches. Often in the past we have had different approaches and systems according to which revenue product or which client segment was being served. In the new approach we only customise where necessary.

The program will affect most of our staff over the period. We have just introduced the new Client Relationship Management system to our call centres (about 3,000 staff). In further releases during this year we will add case and correspondence management, content management, reporting and record keeping to about 12,000 staff. In our final releases during 2007/08 we will replace all our processing systems, and nearly all staff will be involved. The total cost is about $\$ 450$ million.

A key learning from previous attempts at large scale change was that we needed to address the program and manage risks at three levels - Strategic Positioning and Intent, Program Design and Development, and Program Implementation. 


\section{Figure 3}

\section{A strategic approach}

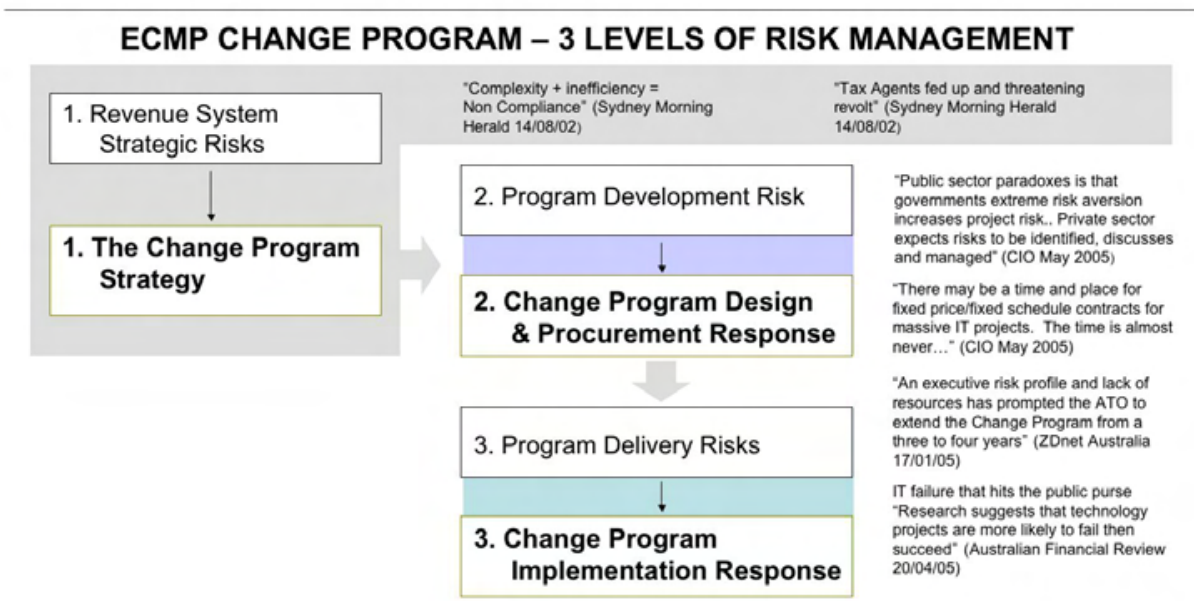

We also decided to separate our approach into very deliberate phases.

\section{Figure 4}

\section{Change Program timeframe and phases}

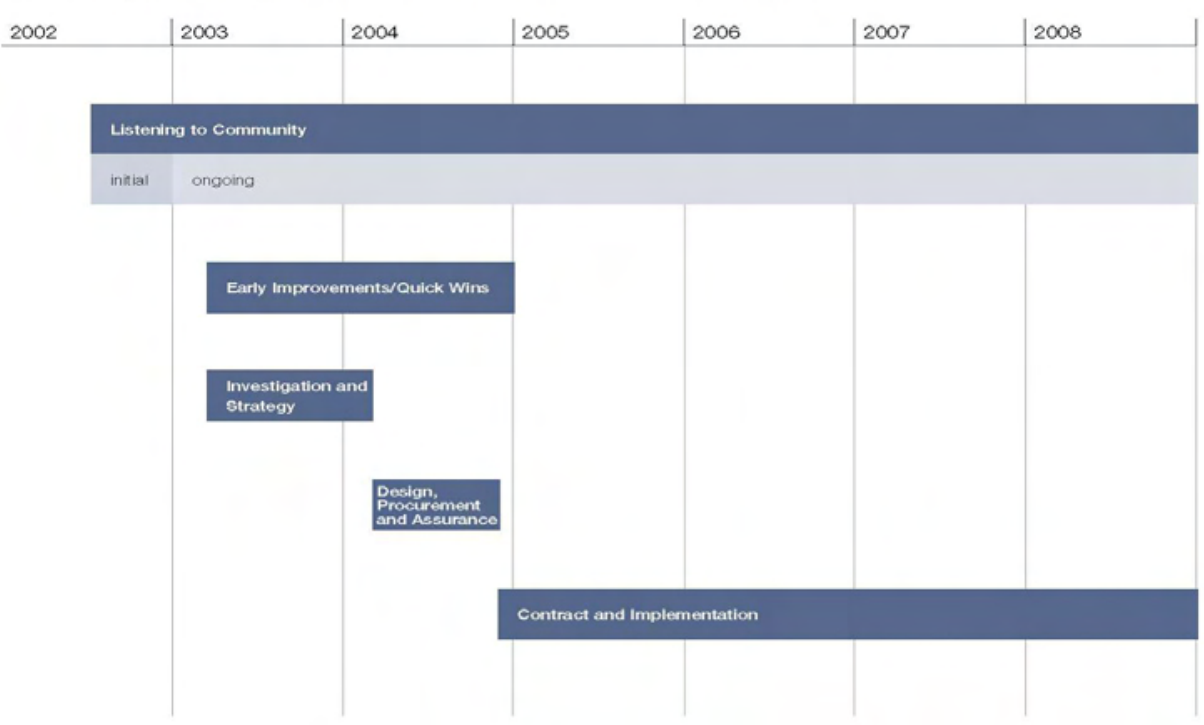

\section{Strategic Positioning and Intent}

A key part of strategic positioning is that the Change Program is explicitly linked to, and supports delivery of, the ATO Business Model. 


\section{Figure 5}

\section{Relationship of the Easier, Cheaper and More Personalised Change Program to the Tax Office Business Model}

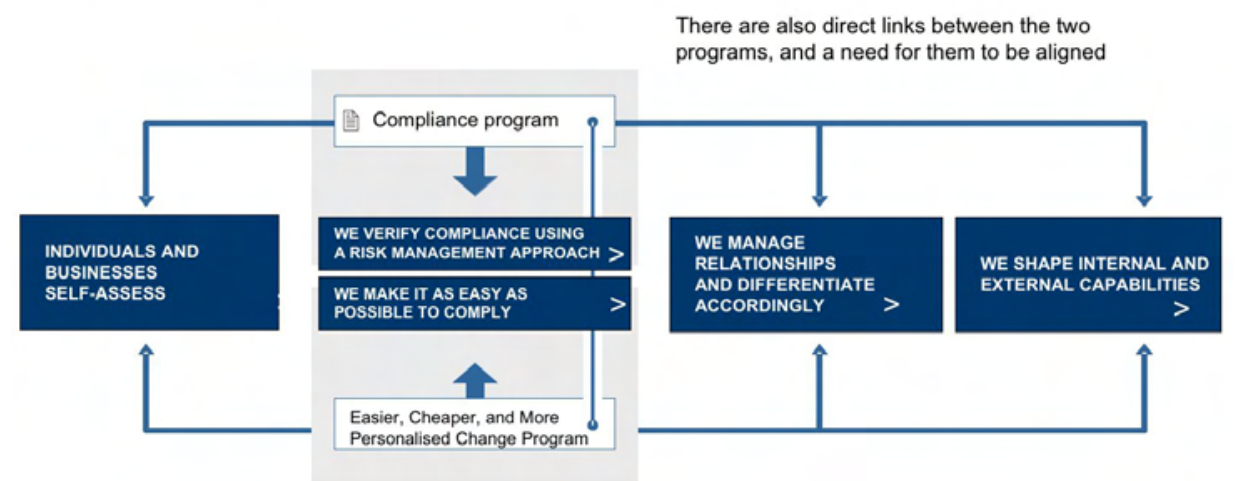

While we were developing the Change Program, we realised that something we were in want of was a clearly articulated business model - what is our business philosophy, what is the way we thing about the business, starting from the self-assessment system which itself conditions a lot of our approaches? There are two main strategic planks in the model. One is the compliance strategy and program. Under a self assessment system you need risk based compliance approaches. The second is the Making it Easy to Comply strategy, of which the main component is the Change Program.

Some additional aspects of the strategic positioning were as follows.

- A contract with the community. Having listened to the community we fed back to the community what we had heard through a booklet (also provided electronically on our web site) entitled 'Making it Easier to Comply'. We first published this in 2003. We put it out every year to say 'these are the commitments we are making in terms of some really specific future products and services we are going to introduce; and this is how we delivered against the commitments made in the previous year'. Making such an external commitment is also useful internally in keeping us focussed on the main strategic intent.

- Both external and internal transformation. Whilst the program started from the external stakeholders' needs we realised early on that we would not be able to sustain and deliver many improvements unless we also transformed our internal capabilities (people, process and technology).

- Emerging community based systems and whole of government. The changes we make are also intended to provide the foundation for a whole range of community based approaches (for example the ability for small businesses 
to lodge and finalise their returns directly from their accounting software), and improved whole of government approaches, for both businesses and individuals.

- Leverage off capabilities and experience of other organisations. When we think hard about our business, most of what the Tax Office does, broken into its component parts, is actually very similar to what a lot of other organisations do. We have taken a strategic position to learn and take product from others, rather than (our traditional approach) do everything ourselves and build our own unique systems and processes.

- $\quad$ Phase the program over the minimum reasonable timeframe. We talked to a number of our colleague revenue agencies and other big organisations around Australia and the world about their experience. A common finding was that many tried to transform too quickly and found there was too much happening in parallel. But an even greater number saw failure as a result of the change taking too long. They were living in two worlds, the new world and the old world for too long. Investment in both worlds was costly and complicated, and people also lost focus. So we chose an ambitious, but feasible, implementation timing as a deliberate trade-off between these two tensions.

- Quick wins. As I mentioned earlier we committed to a significant number of improved products and services across all segments and channels. This bought some critical time to allow us to deliver the underlying changes, and also provided external and internal credibility to the program.

- Top level leadership. The Commissioner led the effort right from the outset, and frankly, in an organisation as complex as the Tax Office, you would not want to try such a large scale change unless this was the case. This was complemented by a number of joint strategy and design activities including the senior management from across the organisation, as well as external expertise at key stages.

\section{Program Design and Development}

Once we had the strategic positioning settled we moved to the second phase of program design and development.

The following were key features of this phase:

- Ongoing engagement with stakeholders. We had completed the initial listening to the community, but the fact is you have to keep at it: reviewing directions and co-design of products, as well as monitoring perceptions and feedback. We found that even as we designed the various products, some of the things we thought we understood out of the listening to the community phase, had to be modified.

- Formal blueprint and transition plan developed throughout 2004. The Solution Blueprint covered the people, process and technology aspects of the future 
design. An integrated Transition Plan set out the sequence and timing of packages of change (or releases) through to 2008.

- A whole-of-program business case. In previous change initiatives we had attempted a separate business case for each component of the change and it never quite stacked up, it never quite justified the investment. It wasn't until we lifted the business case up to the level of the integrated outcomes and benefits that it became viable.

- Selecting off the shelf and transfer technology. Although this particular change initiative is not a technology program, the technology component is critical. Through a number of market tenders we selected a small number of suppliers - one for Client Relationship Management; one for Case and Correspondence Management; one for Content, Document and Records Management; and one for our core processing systems.

- Obtaining the required program management and integration expertise. We are a revenue agency not a program management agency. For a program like this we decided to buy in the expertise of people who do this as their daily living. We also decided we wanted a single program partner with clear overall accountability for delivery across the program. Through an open market exercise we selected Accenture as the Program Implementation Partner. They can and do sub-contract others in, but we deal only with them.

- An outcomes-based fixed-price contract.

Outcomes-based means that the contract deliverables are specified as higher level business outcomes within eight categories.

\section{Figure 6}

\section{Change Program - Measures of Success}

The Change Program will deliver the following outcomes and our success will be measured by KPIs in 5 categories
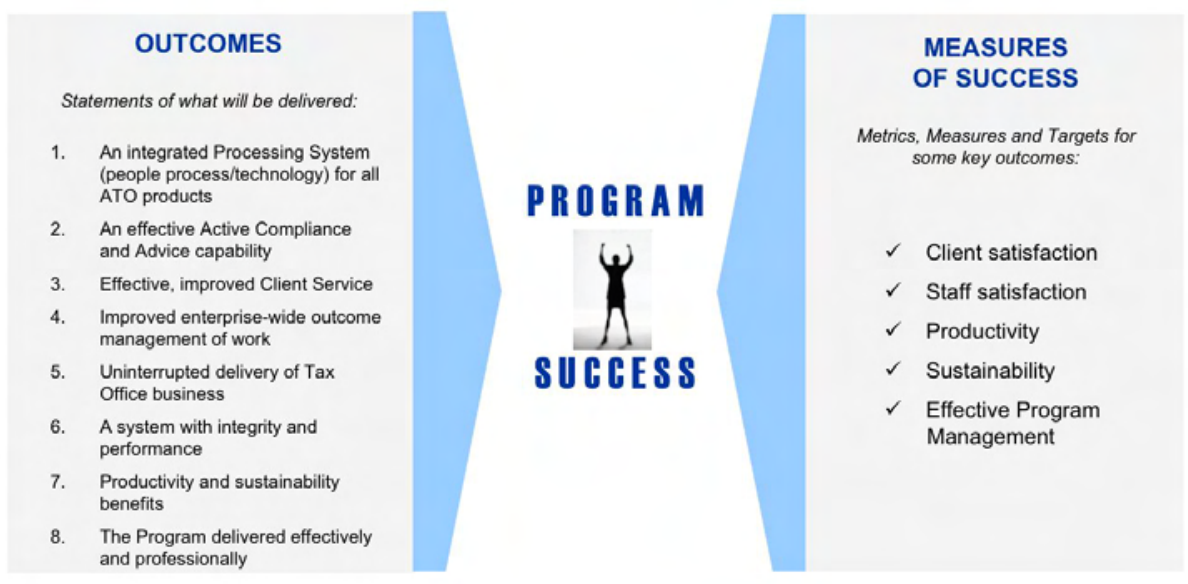
Something we had found out through experience was that if you try to contract to detailed specifications of what you think you need for the next three or four years, your imagination fails you, and sure enough down the track you have countless scope variations and increases. However if you pitch expectations at the outcomes level, they are much more likely to remain valid over the period.

Fixed-price in this case means not only for the partner's consulting fees, but also for our own costs which are about half of the total program costs. If there is a greater use of Tax Office staff than anticipated in the fixed price, the extra cost is underwritten by the program partner. This is possible because they manage the project, and they manage the Tax Office staff who work with them on the project. For us this was fairly innovative.

- Expert independent advice. We selected Capgemini as Independent Assurer to look over both our and Accenture's shoulders. Whilst we may get enmeshed in the daily run of things they are able to step back and point out if we are overlooking key issues. They have been involved in design, planning and implementation phases.

- Procurement practices. We followed Australian National Audit Office best practices, particularly around probity and risk management aspects of the procurement.

- Leadership. There has been a Change Program Steering Committee throughout, comprised of the four Commissioners. We report twice a month as to how we are going and to seek guidance or direction on any major strategic or design issues. This has been going for two and a half years and will continue through the life of the program.

\section{Program Implementation}

Having established the strategic positioning, program design and development, and with key procurement complete, we moved to the major phase of implementation.

It has been mentioned elsewhere that 66 per cent of programs and projects fail and 33 per cent succeed. Of those that fail most are classified as failures of implementation. I have to say, though, unless we had done the work in the prior phases as described above, the task and risks of implementing would be much greater.

Having said that, there are still 'bucket loads' of implementation risks, so we need overt strategies to address these:

- Continuing strong governance and accountability arrangements. I already mentioned the Change Program Steering Committee. Below this, the program design and delivery has been the responsibility of a single integrated Change Program team. When we delivered tax reform we did it in a very devolved 
way. The different revenue product areas had the major responsibilities for introducing the change, including business processes and systems, and, whilst we had an overall Reform Program Office for planning and monitoring, the approach was very decentralised. We have taken a very different approach this time. We have brought the Accenture, business area and IT people into the one team, quite a large team of around 500 people, to form a new Tax Office division for the duration of the program.

- Formal program and project management methodology. Obvious in a sense, but not always easy to make work in an organisation where very large scale program management is not a way of life. We decided to essentially use the methodologies of our program partner and our independent assurer.

- Formal stage gates. The Government has recently introduced the requirement for formal stage gate type approaches in significant projects. This project is not subject to these Government arrangements because it was committed before they came into effect. However we have in any event incorporated a total of ten key stage gates throughout the program. We effectively have a go/no go decision at each of these, and get an independent assessment of how we are going, as well as a self assessment.

- Staying outcomes-focussed and realising benefits. The Tax Office has found this a difficult area in the past. With continuing intensive policy and community agendas, the tendency is to get one project almost finished when another comes rolling over the top. So we have been very intentional this time with a 'formal benefits realisation measurement process' built in, and an ongoing assessment of how we are going against the initial intent and outcomes.

- Supporting existing business operations. Implementation of major change causes a lot of transition issues, so the engagement with the other Tax Office divisions or sub-plans, particularly the compliance and the operations areas of the office, is very intense indeed, to help manage the impact of the changes.

- Growing emphasis on people and change management. Some people have said 'you will need a culture change program to complement the other activities'. We thought about that pretty hard, and concluded people are not going to change their attitudes or approaches until there is something tangibly different in their work life. So we have tailored the approach to people and change management to be much more closely aligned to the period just before they are about to experience something that is significantly different. In a 4-5 year program this is not immediate.

However I mentioned that we directly impacted 3000 staff last year, and will impact 12,000 staff this year. So people and change management is about half of our focus and concentration at this time. 
We have adopted a model to frame our approach. At one end of the spectrum there are some very hard or concrete process and systems elements - for example, of course you have to train people on the new systems and help them with ongoing performance support. There are organisational job design issues to be addressed. That's all very concrete. At the other end there are many softer but equally critical elements such as sponsorship and communications, and behavioural change and expectations.

\section{Figure 7}

\section{People Change Management Approach}

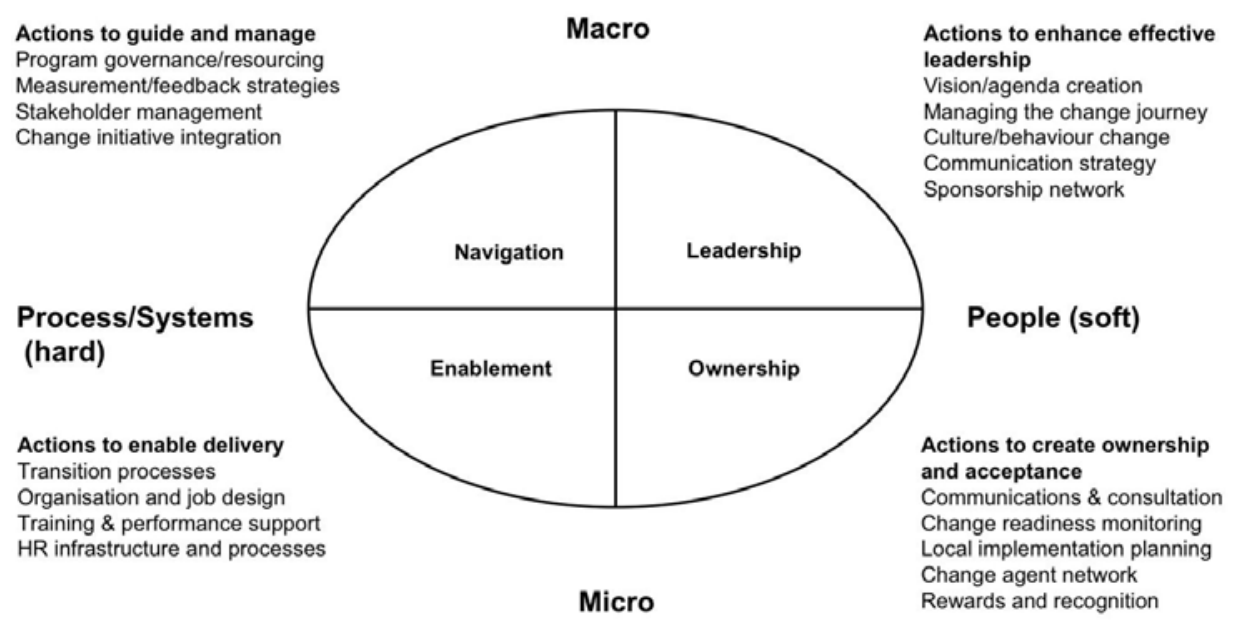

\section{Results and learnings to date.}

With implementation of the major changes well under way we are about half way through the Program. How are we tracking against the original intent?

Most client product and service commitments have been delivered on schedule with some, however, being several months late. Surveys and product uptake indicate we have been particularly successful with tax agents. Individual taxpayers' uptake of enhanced products like e-tax has been very strong. Our biggest challenge remains with business and especially small business where satisfaction levels and uptake are increasing slowly, and from a low base.

As for internal systems and business process releases, we are still on track for the original plan to be completed by 2008. We have had some delays of around six months overall on the first and second of the three main releases, but the first was completed last year and the second is well progressed for completion during 2006. The fixed price means that there has been no material cost increase as a result of these delays. The evidence to date is that we can still achieve all 
of the expected outcomes by 2008, although we have often had to revisit the exact way we do this. Basing the contract on what we want to achieve rather than the detail of how we achieve it, is already paying dividends.

We have some additional learnings from the implementation phase so far:

- Technology. Introducing a new platform entails risk. So far, in the Change Program, where we are introducing several new platforms and systems, most have now settled in, but only after a range of problems - unexpected issues, integration issues - which have been the prime cause of the temporary delays noted above;

- Rapid decision making versus wide engagement. One of the continuing struggles is to find the right balance between the need for well informed but quick decision making, and wide consultation with the rest of the business. Engagement has been intensive but we have also had to recognise when we need to go forward on an 80-90 per cent confidence level rather than 100 per cent;

- The call on other Tax Office business areas. We attempted to factor the costs of this fully into the Business Case but clearly underestimated the level of resource demand on the rest of the Office, to play their critical part in both design and deployment;

- Value of the stage gate reviews. These have been invaluable in forcing us to step back and assess how we are going and making any necessary adjustments; and

- Staying focused. There is a lot of pressure from both inside and outside the organisation to add scope. In a program of this size one of the main tasks is to stay focused. One of the key roles for the leadership team has been to keep the program in line with the original outcomes, and recognise that we cannot deliver everything in the first wave.

\section{Project Management in the broader ATO}

Finally let me reflect on some of the approaches we are taking to program and project management across the Tax Office.

We categorise our projects into policy, compliance and administrative projects and we have literally hundreds of them.

A part of the challenge is the sheer number and variety of projects that exist at any one time. At any one time, we have 100 or so policy projects at various stage of maturity. We also have a large number of compliance projects, not all of which are managed formally as projects at the moment, and we have a number of administrative projects. The Change Program is easily the biggest of these and, in fact, through the Change Program we have closed down a number of other projects to keep the focus on the main game. 
Apart from the Change Program, the main corporate project management focus to date has been on policy and on IT projects. There has been hesitancy in some other areas to apply project management approaches. This might be because of behaviour, attitude or cultural issues or just unfamiliarity. But there are also some more direct barriers. These include:

- poor understanding of how to differentiate between project and business as usual work;

- a perception, often justified, that full project management methods are too complicated for many situations, so that 'one size fits all' is not appropriate; and/or

- limited integration with other governance and management processes e.g. business planning in the annual planning cycle and regular governance reporting.

To address these and other issues, and with the Commissioners' endorsement, we commenced a Project Management Improvement project about 18 months ago.

Some initiatives at the governance level include:

- integration of project management into existing business processes such as business planning, to achieve an equivalent standard of governance and reduce duplication;

- clearer project sponsor and manager accountabilities;

- introduction of formal review points (stage gates) for major programs and projects; and

- review of the relevant corporate policies, including a new Practice Statement for project management and a formal assurance process - particularly important in the complex and decentralised environment in which most of our projects necessarily live.

At the methodology level we are developing:

- clearer 'program' as opposed to individual 'project' approaches, recognising that it is very common for projects to be part of a larger program;

- uniform approaches to project identification and profiling;

- methodologies that can be more readily tailored to suit project characteristics, including a 3 Tiered Approach, with more rigour required for larger high impact projects (Tier 1) and less for smaller low impact projects (Tier 3);

- alignment of related methodologies and disciplines (e.g. change management, design, systems development) within the overarching project management approaches; and

- appropriate technology support to assist managers and staff in project governance and management. 


\section{Figure 8}

\section{How are we using the learnings to improve the Tax Office's Project Management approach?}

\section{Tiered approach to profiling projects}

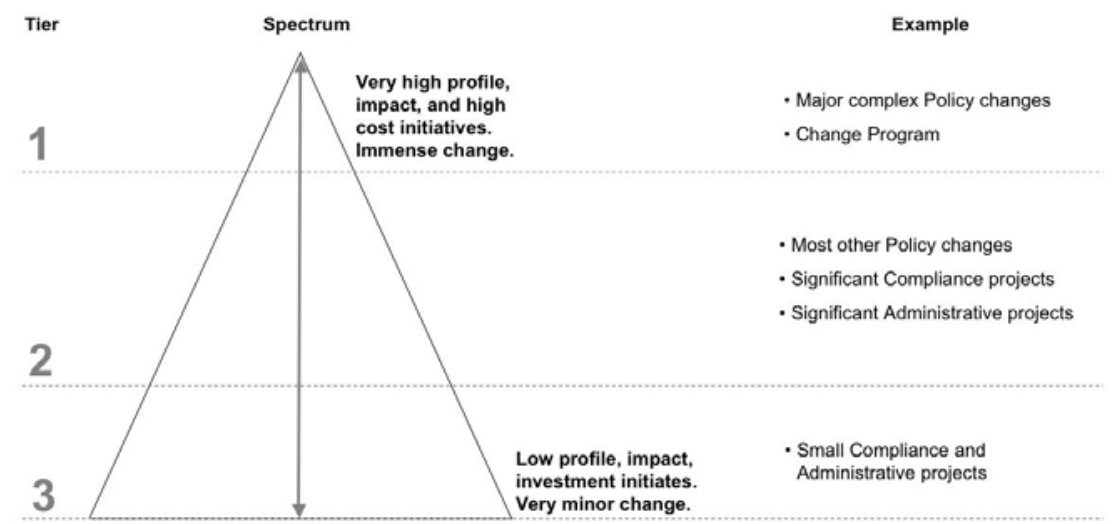

These initiatives are, in some cases, building on the learnings from the Change Program. However, they also recognise that such approaches would be 'overkill' for many of our projects. The work is showing promising signs of bringing a practical approach to achieving the undoubted benefits of project management approaches, without burdening managers out of all proportion to the value.

\section{Conclusion}

This chapter has focussed primarily on the Tax Office Change Program as a case study. When you hear that sobering statistic that 66 per cent of projects fail you could be forgiven for believing that embarking on such a program is either foolhardy or courageous.

In our case we concluded there was no option but to change, and to do so in an ambitious way, in order to fundamentally address the growing range of issues and expectations. What we have tried to do, is to mitigate the undoubted risks, by learning from our own and others' experience, and so improve the odds in our favour. So far we have negotiated a range of issues and obstacles, and remain essentially on track.

We can expect that many more issues will need to be navigated throughout the remainder of the program. The decisions that have positioned the program at each of the strategy, design, and implementation phases have undoubtedly helped. But from here it will be continuing attention to rigorous program and change management approaches, anticipation of those issues that might be 
predicted, and responsiveness to the unexpected, that will be the prerequisites of success. 